\title{
Right ventricular myocardial infarction in the era of primary percutaneous coronary intervention
}

\author{
Koc L $\mathrm{L}^{1,2}$, Ondrus $\mathrm{T}^{1,2}$, Fila $\mathrm{P}^{2,3}$, Richter $\mathrm{S}^{4}$, Kala $\mathrm{P}^{1,2}$ \\ Department of Internal Medicine and Cardiology, University Hospital Brno, Brno, Czech Republic. \\ kala.petr@fnbrno.cz
}

\begin{abstract}
Right ventricular involvement (RVMI) is a relatively frequent complication in patients developing ST-elevation acute myocardial infarction. The initial diagnosis is most often established using electrocardiography or echocardiography. The gold standard among imaging techniques is cardiac magnetic resonance, which allows to distinguish between reversible and irreversible myocardial damage. The key treatment strategy is emergent revascularization by primary percutaneous coronary intervention whereas patients with hypotension and cardiogenic shock due to the RVMI require fluid replacement and catecholamine therapy. In cases where the shock state progresses despite an adequate management, short- or, possibly, long-term mechanical assist device should be implanted either percutaneously or surgically. Despite appreciable advances in the diagnosis and management, RVMI remains an independent predictor of early as well as late complications (Fig. 6, Ref. 62). Text in PDF www.elis.sk KEY WORDS: right ventricle myocardial infarction, primary $\mathrm{PCI}, \mathrm{CMR}$, mechanical circulatory support, echocardiography.
\end{abstract}

\section{Introduction}

Experimental animal models showed that induced RV injury did not markedly impact overall hemodynamic status $(1,2)$, myocardial infarction involving the right ventricle (RVMI) has long been viewed as a benign lesion not attracting major attention in the relevant literature. While the first case report of complications experienced by a patient developing proximal right coronary artery occlusion was published as early as 1931 (3), the clinical syndrome typically associated with RVMI was not reported until 1974 (4). While isolated RVMI occurs seldom (5), in patients with left ventricular infarction, depending on its location, may be present in up to $65 \%$ of cases (6). Early identification of the patients developing RVMI is critical both for their treatment and prognosis. Management of the patients with clinically manifest $\mathrm{RV}$ involvement requires a specific approach, primarily in terms

${ }^{1}$ Department of Internal Medicine and Cardiology, University Hospital Brno, Brno, Czech Republic, ${ }^{2}$ Faculty of Medicine, Masaryk University, Brno, Czech Republic, ${ }^{3}$ Center of Cardiovascular and Transplant Surgery, Brno, Czech Republic, and ${ }^{4}$ Department of Radiology and Nuclear Medicine, University Hospital Brno, Brno, Czech Republic

Address for correspondence: P. Kala, Assoc Prof, MD, PhD, FESC, FSCAI, Department of Internal Medicine and Cardiology, University Hospital Brno and Faculty of Medicine of Masaryk University Jihlavska 20, CZ-625 00 Brno, Czech Republic.

Phone: +420.532.232648, Fax: +420.532.232725

Acknowledgements: Supported by a Grant from the Ministry of Health of the Czech Republic, NT13767-4. of fluid management to optimize RV preload. Moreover, RVMI patients are at a higher risk of developing both short- and longterm complications.

\section{Diagnosis}

\section{Clinical assessment}

Symptoms of the patients with clinically manifest RVMI are related to their hemodynamic status. The blood stagnates in the vascular system in front of a dysfunctional right ventricle, which is unable to provide adequate left ventricular preload, resulting in a decreased cardiac output. Based on that, the typical trias of symptoms occurs - hypotension, jugular vein distension and absence of pulmonary congestion (7). The patients with RV dilatation may also develop systolic murmur associated with tricuspid regurgitation. The increase in venous return on inspiration in the patients with a failing RV may manifest by a marked jugular vein distension (Kussmaul's sign); additionally, paradoxical pulse may also be present (8).

\section{Electrocardiography}

Standard 12-lead ECG provides information mainly about the left ventricle. For the monitoring of $R V$, right sided leads $V_{3} R-V_{6} R$, placed on the chest in mirror positions to standard leads, are critical. Right ventricular MI is indicated particularly by an ST-segment elevation of $0.1 \mathrm{mV}$ or higher in precordial lead $\mathrm{V}_{4} \mathrm{R}(9-12)$ (Fig. 1). The advantages of ECG include its wide availability and the possibility to repeat the examination. However, the changes detected by ECG are transient and in cases, where the right-sided 


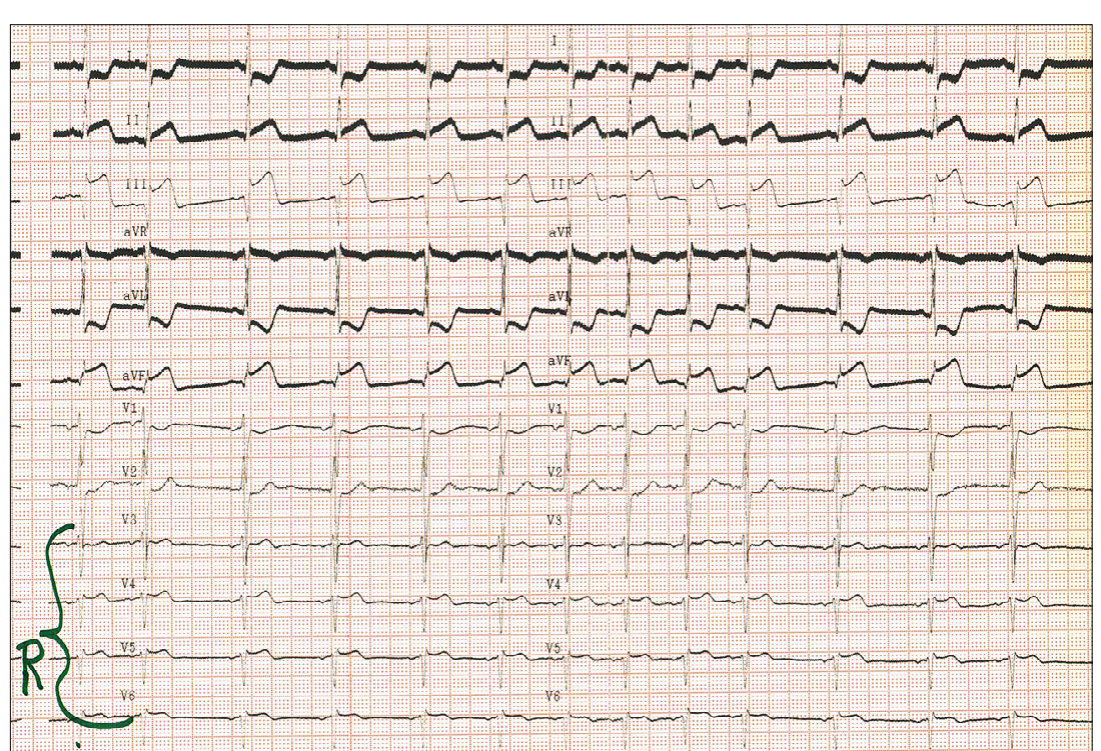

Fig. 1. Electrocardiogram showing an inferior wall STEMI with ST-segment elevation in right precordial leads, indicating RVMI.

leads are recorded with a delay, the elevations in lead $V_{4} R$ may no longer be obvious (13).

\section{Echocardiography}

In clinical practice, echocardiography is the most precious imaging technique allowing to assess the structure and function of the heart in the patient developing an acute MI. The main advantages of this technique include, in particular, its wide availability, repeatability, and the possibility of bedside assessment. Echocardiography allows to assess the function of both ventricles, valve function, and to image any MI-related complications. However, retrosternal position of $\mathrm{RV}$, its trabecularization and complex shape make it especially difficult to assess with echocardiographic techniques. If assessing RV involvement in MI patients exclusively on the basis of the presence of segmental kinetic impairment and dilatation, the sensitivity of echocardiography is inferior to the cardiac magnetic resonance imaging (CMR) (6). Hence, a comprehensive echocardiographic examination of the right ventricle should include a determination of quantitative functional parameters (Fig. 2).

Tricuspid annular plane systolic excursion (TAPSE) or tricuspid annular motion (TAM) is a method to measure the distance of systolic excursion of the lateral portion of the RV annular segment using M-mode echocardiography in the apical four-chamber view. Therefore, M-mode cursor is placed through the lateral tricuspid annulus. As RV contraction is caused by predominantly longitudinally oriented fibres, the amplitude of the systolic motion of the tricuspid anulus reflects global RV systolic function, with a reduced RV function indicated by a TAPSE $<16 \mathrm{~mm}$ (14) (Fig. 2, Panel B). The main advantages of TAPSE include its simplicity and high reproducibility, whereas disadvantages include possible volume and angle dependency (15).
The technique of tissue Doppler imaging (TDI) is capable of detecting signals of low velocity and high amplitude generated by the moving myocardium (16). The same as TAPSE, TDI assesses particularly the longitudinal component of myocardial contraction. Placing the sampling volume on the tricuspid anulus at the site of the anterior cusp of the tricuspid valve will reveal the typical curve consistent with the velocity of myocardial excursions. A positive excursion represents myocardial contraction (17) with velocity S` being measured at its peak. While values considered normal are those $\mathrm{S}^{`}>10 \mathrm{~cm} / \mathrm{s}$, abnormal ones indicate decreased RV systolic function which, in MI patients, allows to identify individuals with RV involvement (18) (19) (Fig. 2, Panel C). The pros and cons of TDI are similar to those encountered with TAPSE (14).

The myocardial perfusion index (MPI), occasionally also referred as the Tei index, is calculated as the ratio of isovolumic time divided by ejection time(20) (Fig. 3). These variables are obtained by assessing the blood flow rates through the tricuspid valve using pulsed-wave Doppler echocardiography or TDI. The MPI is used to assess both RV systolic and diastolic function and, given the combination of several time intervals, the technique can identify even minimal changes in RV function. Thus, even less extensive lesions, which may remain unrecognized by routine echocardiography examination, can be detected using MPI (21). The upper reference limit of MPI is 0.4 by pulsed Doppler and 0.55 , when using TDI (14), and increased values of MPI predicts the development of cardiovascular complications in patients with acute myocardial infarction (22). Advantages of the technique include reasonable reproducibility, whereas its disadvantages include inferior reliability in the patients with irregular R-R intervals and dependence on RV filling (20).

The fractional area change (FAC) is assessed by marking the RV end-diastolic area (RVDA) and RV end-systolic area (RVSA) in apical four-chamber view and the following calculation (RVDA - RVSA/RVDA $\times 100$ (23), whereby a normal value is $35 \%$ and over (14). Right ventricular FAC correlates well with the RV ejection fraction as determined by CMR (24), with a low FAC value in individuals having developed an acute MI being a predictor of both total and cardiovascular mortality and development of heart failure (25). The drawbacks of RV FAC include its inferior reproducibility and relatively higher inter-individual variability (depending on the observer's experience).

Speckle-tracking echocardiography (occasionally also referred to as 2D strain) allows to assess global and regional myocardial contractility. A speckle is a unique pattern occurring on ultrasound passing through a tissue. Analysis of the mutual motion of individual speckles enables to generate deformation curves of individual myocardial segments and, using an algorithm, also to average the 


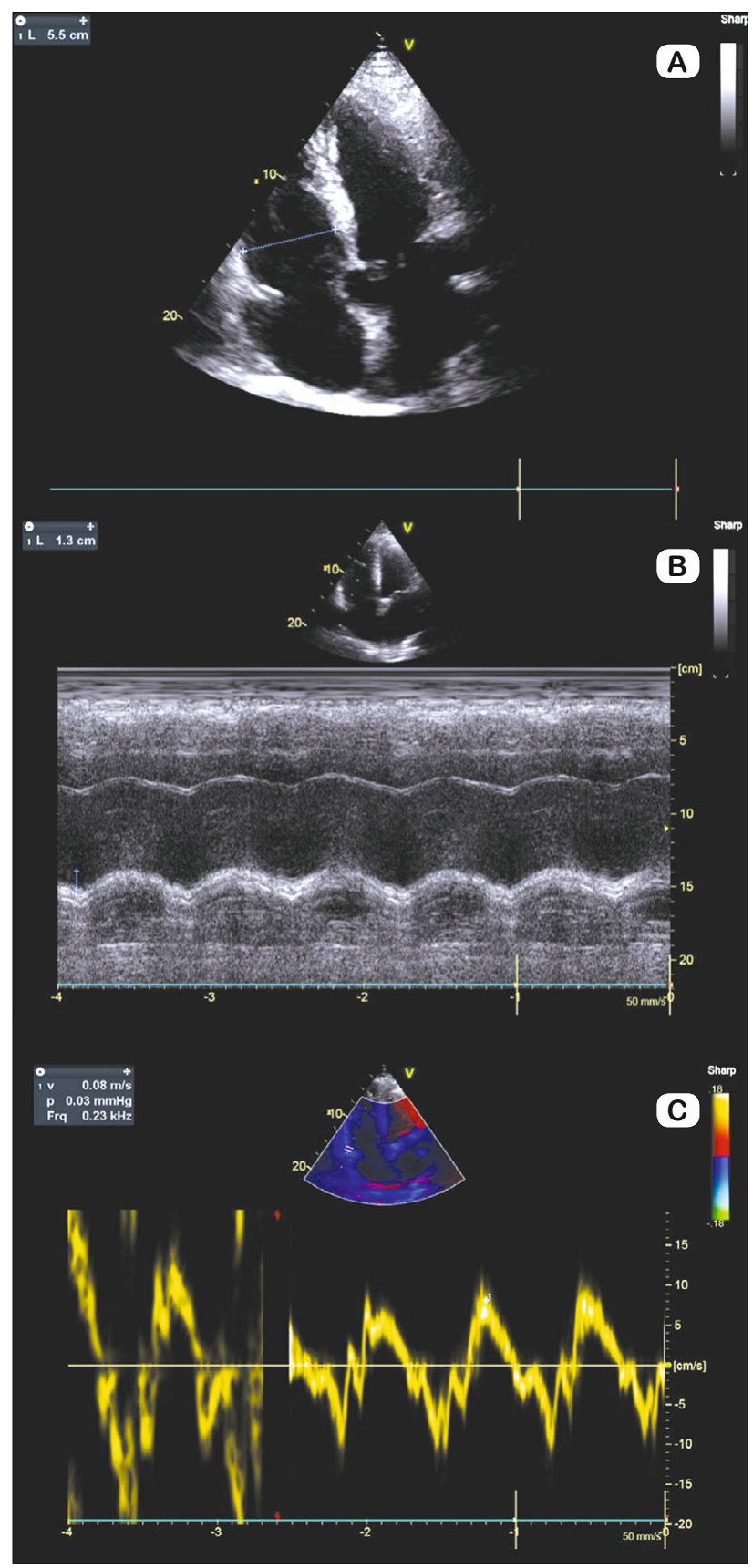

Fig. 2 Echocardiographic assessment of dilatation and systolic dysfunction of right ventricle in RVMI patient. Panel A. The right ventricle diameter of $55 \mathrm{~mm}$ at the basal level. Panel B. Reduced tricuspid annular plane systolic excursion of $13 \mathrm{~mm}$. Panel C. Reduced velocity $S^{`}$ of $0.08 \mathrm{~m} / \mathrm{s}$ measured using tissue Doppler imaging.

myocardial strain of the entire ventricle, i.e., the percentage change of its deformation (26). In the context of RV, the global longitudinal strain is derived from three evaluated segments of RV free wall. As abnormal is considered value $>-20 \%$ and more (23). The advantage of the technique is an angle-independency, while its disadvantages include its higher time-consuming nature and the need for high-quality imaging. Hutyra et al analysed data of a series of 55 acute MI survivors showing ST-segment elevations in the posterior wall treated by percutaneous coronary intervention (PCI). The patients had an echocardiographic examination on the day of MI and subsequently on Day 5 post-MI, with CMR added at one month. Analysis of RV myocardial deformation using peak systolic longitudinal strain allowed for early predictions of RV myocardial scarring to be subsequently verified by CMR (27).

\section{Magnetic resonance imaging}

Cardiac magnetic resonance (CMR) imaging is considered the gold standard among RV imaging techniques. Cine images allow an accurate determination of RV volumes, myocardial mass, ejection fraction and assessment of individual segment kinetics (28). Moreover, CMR is able to furnish information about the myocardial tissue characteristics. Myocardial oedema, as an acute consequence of hypoperfusion, can be specifically detected using a T2-weighted image (29). Irreversible myocardial injury can be imaged using late gadolinium enhancement. While the contrast is gradually washed out from an intact myocardium, in irreversibly damaged regions, the agent remains longer given the less dense vasculature thus enabling visualization the infarct scar $(30,31)$ (Fig. 4). As the result, we are able not only to determine the extent of RV myocardial involvement but, also, to distinguish stunned and still viable myocardium from a necrotic one in the patients in the acute stage of MI.

In the patients with ST-segment elevation myocardial infarction (STEMI) treated by primary PCI (PPCI) and examined, in the acute stage of MI, by CMR, the right ventricle was damaged in $16.4-57 \%$ of cases $(6,28,31-34)$. Right ventricular involvement was associated not only with posterior but, also, anterior wall STEMI, the latter in $54 \%$ of the patients (28), being a strong independent prognostic factor. Those with extensive RV involvement and dysfunction were found to be at higher risk of developing cardiovascular complications (33). By contrast, the prognosis of the patients in the acute stage of STEMI to have only myocardial oedema, as documented by CMR without signs of irreversible ischemic lesions, was identical with those showing absolutely no RV involvement in the same scenario (32).

\section{Treatment}

The state-of-the-art strategy for treating acute MI with ongoing ischemia, especially with ST-elevations, is emergent invasive coronary angiography followed by PPCI, whenever indicated. Even in the case of RVMI, early and successful revascularization results in less extensive RV myocardial necrosis $(32,35)$. Right coronary artery is the most common infarct related artery in RVMI, with the prevailing location of the culprit lesion proximal to origin of the RV branches(36) (Fig. 5). Optimal revascularization with emphasis on optimal flow in RV branches is crucial (Fig. 6), because postinterventional angiographic status of TIMI flow $<2$ in at least one RV branch after PCI was an independent predictor of right ventricular myocardial necrosis(34). RVMI is associated also with the location of the culprit lesion in the left circumflex 


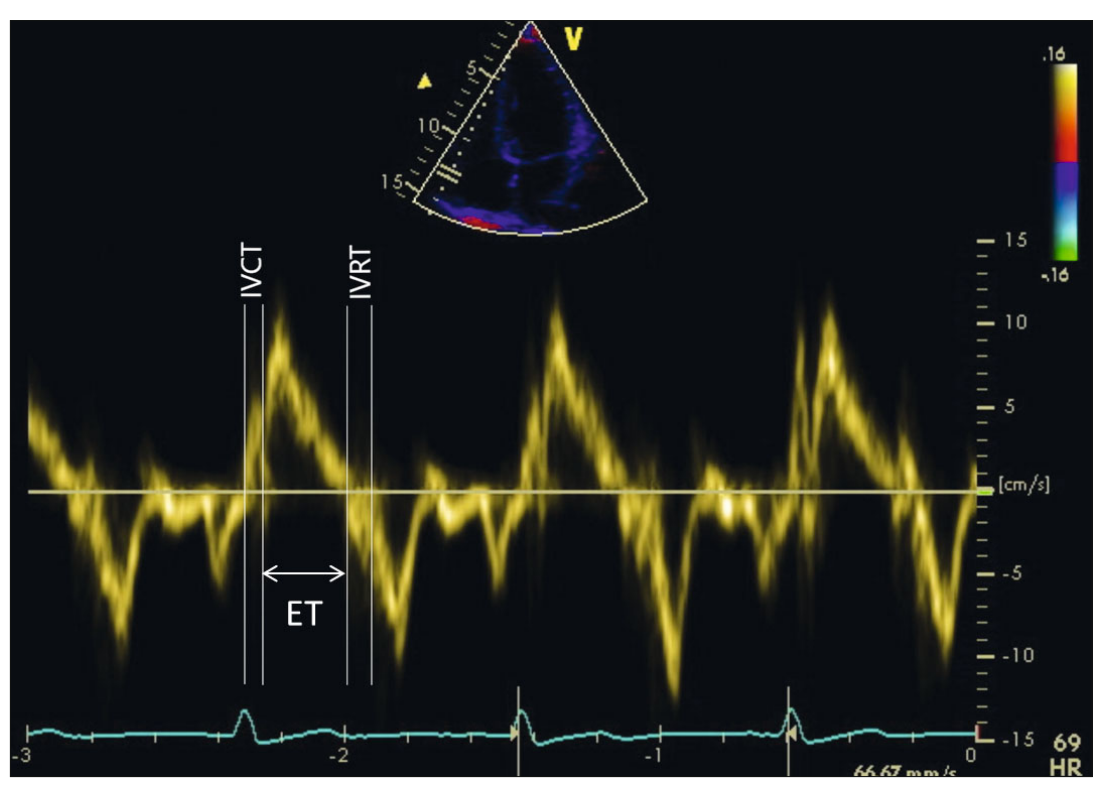

Fig. 3. Calculation of right ventricular myocardial performance index by tissue Doppler. MPI $=($ IVCT + IVRT $) /$ ET. IVCT - isovolumic contraction time, IVRT - isovolumic relaxation time, ET- ejection time.

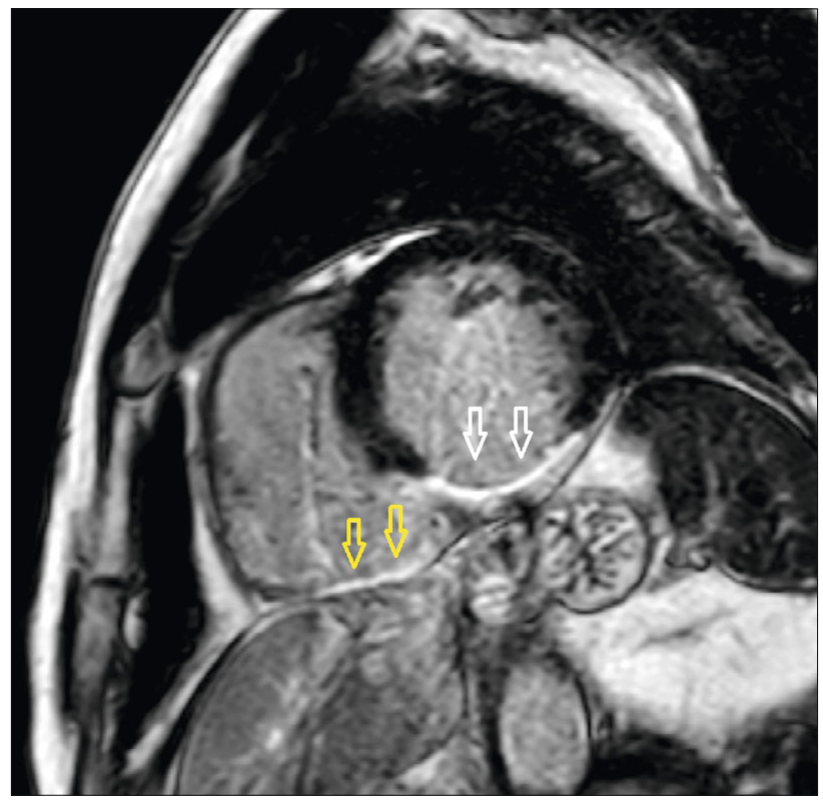

Fig. 4. Assessment of RVMI by cardiac magnetic resonance. Myocardial thinning and late gadolinium enhancement of left ventricle inferior wall (white arrows) and right ventricle (yellow arrows).

artery(32). When RVMI is detected in the patients with the culprit lesion in the left main or left anterior descending artery, the left anterior descending artery usually wraps around the left ventricle apex, terminating in the inferior wall(6).

In cases, where RVMI results in RV dysfunction, the right ventricle is unable to secure an adequate left ventricular preload entailing a decrease in cardiac output and development of systemic hypotension. Because of the RV volume dependence (37), it is critical to avoid using vasodilators further decreasing RV filling (nitrates, diuretics) and, by contrast, to perform fluid challenge (38). However, the specific hemodynamic status is always to be considered. In the patients failing to respond to fluid challenge, further volume expansion is to be performed with extra caution and to assess the patient's hemodynamic status, whether invasively or non-invasively. Patients benefiting most from the initial fluid administration should include those without an apparent lung congestion and central venous pressure below $15 \mathrm{mmHg}(37,39)$. In hypotensive patients with a low cardiac output persisting despite a fluid administration, an option is administration of inotropic agents (dobutamine, in particular), which in the patients developing RVMI has been shown to lead to an increase in the cardiac index, pulse index as well as RV ejection fraction(40).

The last option to maintain circulation and ensure sufficient organ perfusion in the patients with cardiogenic shock progressing despite revascularization and optimal pharmacotherapy is a mechanical circulatory support.

Intra-aortic balloon counter-pulsation (IABC) is a technique of passive mechanical support designed to improve - in the event of RV failure - especially coronary perfusion (41) thereby improving RV function (42).

The Impella RP (Abiomed, Danvers, MA, USA) is an active mechanical RV support device consisting of a microaxial blood pump inserted percutaneously into the right ventricle. The device draws the blood from the vena cava inferior bringing it to the pulmonary artery at a maximum blood flow rates of 4 litres per minute. In the study enrolling 60 patients with a refractory RV failure (due to left ventricular assist device [LVAD] implantation) following cardiac surgery, heart transplantation or MI, implantation of the Impella RV resulted in an immediate improvement of their hemodynamic status with 30-day survival since device implantation in $72 \%$ of the patients (43). Gramegna et al reported on a series of 5 patients experiencing acute posterior wall MI with failed PCI of the right coronary artery, in whom inotropic support and $\mathrm{IABC}$ were followed by refractory RV failure. Implantation of the Impella RP device resulted in an immediate improvement of their hemodynamic status. Four patients showed RV function normalization over time and all survived 30 days after Impella implantation (44).

The TandemHeart right ventricular assist device (TH-RVAD) (TandemLife, Pittsburgh, PA, USA) is an extracorporeal centrifugal pump with an inflow cannula inserted percutaneously from the groin to the right atrium drawing the blood subsequently brought through an outflow cannula to the pulmonary artery via the jugular vein. Another option is to use a single biluminal (inflow and 


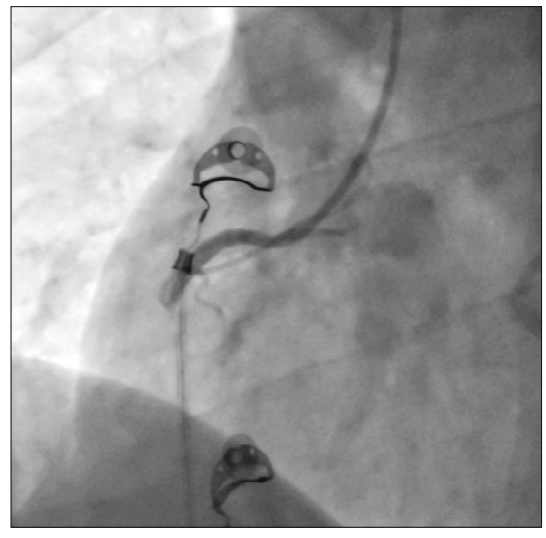

Fig. 5. Angiogram showing occlusion of the proximal right coronary artery.

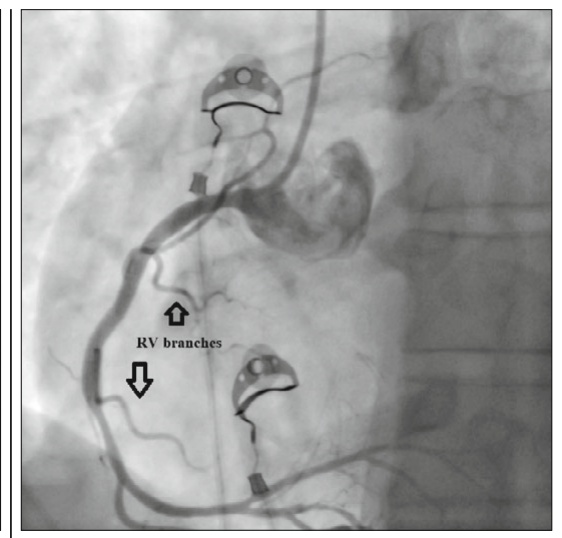

Fig. 6. Angiogram showing the right coronary artery post-revascularization.

age does not essentially impact the hemodynamic status (2). It was only later that RV function was shown to be an independent prognostic factor (47-49). Right ventricular involvement in patients with acute MI treated by thrombolysis was associated with a higher risk of death, higher incidence of arrhythmias and higher probability of experiencing cardiogenic shock during the acute stage of disease $(50,51)$. Likewise, mortality of the patients with cardiogenic shock due to RV involvement was similar to that of the patients with cardiogenic shock as the result of left ventricular dysfunction (52). The introduction of PPCI into clinical practice was followed by a rapid improvement of prognosis of the patients with acute MI. Compared with thrombolytic therapy,

outflow) cannula advanced through the internal jugular vein to the pulmonary artery. In the retrospective study assessing a total of 46 patients with TH-RVAD implantation for RV failure, while reporting immediate improvement of hemodynamic status, in-hospital mortality was $57 \%$ (45).

Extracorporeal membrane oxygenation (ECMO) is another technique of active mechanical circulatory support inserted by a catheter. In V-A mode, the inflow cannula is placed in the right atrium via the femoral vein. Unlike the Impella RP and TH-RVAD, the blood bypasses the right and left ventricles to enter the oxygenator and pump the blood into the aorta via the outflow cannula inserted into the femoral artery. The technique results in decompression of the failing right ventricle, a decrease in pulmonary artery pressure and provide for sufficient blood flow through organs. A draw back of the technique is an increase in left ventricular afterload, which can be solved by implantation of IABC.

Given the low number of patients managed by temporary RV mechanical assist devices, the body of clinical experience with the technique is small. While the mentioned reports suggest an improved hemodynamic after placement of a temporary mechanical support device to the critically ill, no randomized studies have been published to date documenting the superiority of this strategy over conservative therapy in reducing mortality rates.

While no permanent mechanical RV support device is available, some centres use the modified permanent Heartware (Medtronic Inc., Minnesota, MN, USA) or HeartMate 3 (Abbott, St. Paul, MN, USA) left-ventricular assist devices employed during cardiac surgery procedures in lieu of right-sided mechanical support; whatever the case, it is off-label use (46). The only long-term "support" for the right ventricle is total artificial heart as a bridge to transplant. The timing is most important in right-heart support. The bigger mistake is to wait than to make an early implantation.

\section{Prognosis}

The importance of RV involvement was unjustly disregarded in the past, and some experimental studies suggested that the dam- the patients treated by PPCI showed a smaller extent of myocardial necrosis (53), lower mortality rates (54) and were at lower risk of reinfarction (55). While some earlier studies reported that, unlike the left ventricle, the right ventricle was highly resistant to ischemia, with its function normalizing after an MI independently of whether or not infract artery recanalization has been successful $(56,57,58)$, more recent studies clearly demonstrated that, also in the case of RVMI, early and successful revascularization by PPCI resulted in less extensive RV myocardial necrosis and markedly improved short- as well as long term prognosis of the patients (32, $34,59,60)$. Nonetheless, persisting RV dysfunction after an acute $\mathrm{MI}$ is an independent predictor of a relatively poorer prognosis both in the patients treated predominantly by thrombolysis $(25$, $61)$ and those undergoing PPCI $(32,33,62)$.

\section{Conclusion}

Right ventricular myocardial infarction during MI is a relatively frequent complication in the patients developing an acute MI, especially STEMI. The initial diagnosis of RVMI documented by ECG and echocardiography can be confirmed by CMR as the gold standard in assessing the RV status. The mainstay of treatment is emergency PPCI reducing the extent of myocardial ischemia and - in the patients developing hypotension - fluid balance optimization and inotropic support. In the patients showing a progressive deterioration, implantation of a mechanical circulatory device may be another, and the last option. Despite appreciable advances in the diagnosis and management, RV involvement in acute MI remains an independent predictor of early and late complications.

\section{Learning points}

- In STEMI patients, right ventricular myocardial infarction may be present in up to $65 \%$ of cases.

- ST-segment elevation of $0.1 \mathrm{mV}$ or higher in precordial lead $\mathrm{V}_{4} \mathrm{R}$ is diagnostic for RVMI. 
- Echocardiography is widely available and repeatable, while CMR is considered the gold standard among RV imaging techniques.

- Timely performed primary percutaneous intervention is cornerstone of treatment STEMI patients with RVMI.

- Fluid balance optimization and inotropic support is necessary in the patients developing hypotension.

- Implantation of a mechanical support may be the last option in the patients showing progressive hemodynamic deterioration.

- RVMI remains an independent predictor of early and late complications.

\section{References}

1. Starr I, Jeffers WA, Meade RH. The absence of conspicuous increments of venous pressure after severe damage to the right ventricle of the dog, with a discussion of the relation between clinical congestive failure and heart disease. Am Heart J 1943; 26 (3): 291-301.

2. Kagan A. Dynamic responses of the right ventricle following extensive damage by cauterization. Circulation 1952; 5 (6): 816-823.

3. Sanders AO. Coronary thrombosis with complete heart-block and relative ventricular tachycardia a case report. Am Heart J 1931; 6 (6): $820-823$.

4. Cohn JN, Guiha NH, Broder MI, Limas CJ. Right ventricular infarction. Clinical and hemodynamic features. Am J Cardiol 1974; 33 (2): 209-214.

5. Andersn HR, Falk E, Nielsen D. Right ventricular infarction: Frequency, size and topography in coronary heart disease: A prospective study comprising 107 consecutive autopsies from a coronary care unit. J Am Coll Cardiol 1987; 10 (6): 1223-1232.

6. Jensen CJ, Jochims M, Hunold P, Sabin GV, Schlosser T, Bruder O. Right Ventricular Involvement in Acute Left Ventricular Myocardial Infarction: Prognostic Implications of MRI Findings. Am J Roentgenol 2010; 194 (3): 592-598.

7. Dell'Italia LJ. Physical Examination for Exclusion of Hemodynamically Important Right Ventricular Infarction. Ann Intern Med 1983; 99 (5): 608 .

8. Cintron GB, Hernandez E, Linares E, Aranda JM. Bedside recognition, incidence and clinical course of right ventricular infarction. Am J Cardiol 1981; 47 (2): 224-227.

9. Erhardt LR, Sjögren A, Wahlberg I. Single right-sided precordial lead in the diagnosis of right ventricular involvement in inferior myocardial infarction. Am Heart J 1976; 91 (5): 571-576.

10. Candell-Riera J, Figueras J, Valle V, Alvarez A, Gutierrez L, Cortadellas $\mathbf{J}$, Cinca $\mathbf{J}$ et al. Right ventricular infarction: relationships between ST segment elevation in V4R and hemodynamic, scintigraphic, and echocardiographic findings in patients with acute inferior myocardial infarction. Am Heart J 1981; 101 (3): 281-287.

11. Croft CH, Nicod P, Corbett JR, Lewis SE, Huxley R, Mukharji $\mathbf{J}$, Willerson JT et al. Detection of acute right ventricular infarction by right precordial electrocardiography. Am J Cardiol 1982; 50 (3): 421-427.

12. Braat SH, Brugada P, De Zwaan C, Den Dulk K, Wellens HJ. Right and left ventricular ejection fraction in acute inferior wall infarction with or without ST segment elevation in lead V4R. J Am Coll Cardiol 1984; 4 (5): 940-944.
13. Klein HO, Tordjman T, Ninio R, Sareli P, Oren V, Lang R, Gefen $\mathbf{J}$ et al. The early recognition of right ventricular infarction: diagnostic accuracy of the electrocardiographic V4R lead. Circulation 1983; 67 (3): $558-565$.

14. Rudski LG, Lai WW, Afilalo J, Hua L, Handschumacher MD, Chandrasekaran K, Solomon SD et al. Guidelines for the echocardiographic assessment of the right heart in adults: a report from the American Society of Echocardiography endorsed by the European Association of Echocardiography, a registered branch of the European Society of Cardiology, and the Canadian Society of Echocardiography. J Am Soc Echocardiogr Off Publ Am Soc Echocardiogr 2010; 23 (7): 685-713.

15. Jones N, Burns AT, Prior DL. Echocardiographic Assessment of the Right Ventricle-State of the Art. Heart Lung Circ 2019; 28 (9): 1339-1350.

16. Isaaz K, Munoz del Romeral L, Lee E, Schiller NB. Quantitation of the motion of the cardiac base in normal subjects by Doppler echocardiography. J Am Soc Echocardiogr Off Publ Am Soc Echocardiogr 1993; 6 (2): 166-176.

17. Mahjoub Y, Pila C, Friggeri A, Zogheib E, Lobjoie E, Tinturier F, Galy $\mathbf{C}$ et al. Assessing fluid responsiveness in critically ill patients: Falsepositive pulse pressure variation is detected by Doppler echocardiographic evaluation of the right ventricle. Crit Care Med 2009; 37 (9): 2570-2575.

18. Oguzhan A, Abaci A, Eryol NK, Topsakal R, Seyfeli E. Colour Tissue Doppler Echocardiographic Evaluation of Right Ventricular Function in Patients with Right Ventricular Infarction. Cardiology 2003; 100 (1): 41-46.

19. Yilmaz M, Erol MK, Acikel M, Sevimli S, Alp N. Pulsed Doppler tissue imaging can help to identify patients with right ventricular infarction. Heart Vessels 2003; 18 (3): 112-116.

20. Tei C, Dujardin KS, Hodge DO, Bailey KR, McGoon MD, Tajik AJ, Seward SB. Doppler echocardiographic index for assessment of global right ventricular function. J Am Soc Echocardiogr Off Publ Am Soc Echocardiogr 1996; 9 (6): 838-847.

21. Chockalingam A, Gnanavelu G, Alagesan R, Subramaniam T. Myocardial Performance Index in Evaluation of Acute Right Ventricular Myocardial Infarction. Echocardiography 2004; 21 (6): 487-494.

22. Møller JE, Søndergaard E, Poulsen SH, Appleton CP, Egstrup K. Serial Doppler echocardiographic assessment of left and right ventricular performance after a first myocardial infarction. J Am Soc Echocardiogr Off Publ Am Soc Echocardiogr 2001; 14 (4): 249-255.

23. Lang RM, Badano LP, Mor-Avi V, Afilalo J, Armstrong A, Ernande L, Flachskampf FA et al. Recommendations for cardiac chamber quantification by echocardiography in adults: an update from the American Society of Echocardiography and the European Association of Cardiovascular Imaging. J Am Soc Echocardiogr Off Publ Am Soc Echocardiogr 2015; 28 (1): 1-39.e14.

24. Anavekar NS, Gerson D, Skali H, Kwong RY, Kent Yucel E, Solomon SD. Two-Dimensional Assessment of Right Ventricular Function: An Echocardiographic-MRI Correlative Study. Echocardiography 2007; 24 (5): 452-456.

25. Zornoff LAM, Skali H, Pfeffer MA, St. John Sutton M, Rouleau JL, Lamas GA, Plappert T et al. Right ventricular dysfunction and risk of heart failure and mortality after myocardial infarction. J Am Coll Cardiol 2002; 39 (9): 1450-1455.

26. Pirat B, Khoury DS, Hartley CJ, Tiller L, Rao L, Schulz DG, Nagueh SF et al. A novel feature-tracking echocardiographic method for the quantitation of regional myocardial function: validation in an animal model of ischemia-reperfusion. J Am Coll Cardiol 2008; 51 (6): 651-659. 


\section{0-707}

27. Hutyra M, Skála T, Horák D, Köcher M, Tüdös Z, Zapletalová $\mathbf{J}$, Přeček $\mathbf{J}$ et al. Echocardiographic assessment of global longitudinal right ventricular function in patients with an acute inferior ST elevation myocardial infarction and proximal right coronary artery occlusion. Int $\mathrm{J}$ Cardiovasc Imaging 2015; 31 (3): 497-507.

28. Masci PG, Francone M, Desmet W, Ganame J, Todiere G, Donato $\mathbf{R}$, Siciliano $\mathbf{V}$ et al. Right ventricular ischemic injury in patients with acute ST-segment elevation myocardial infarction: characterization with cardiovascular magnetic resonance. Circulation 2010; 122 (14): $1405-1412$.

29. Aletras AH, Tilak GS, Natanzon A, Hsu L-Y, Gonzalez FM, Hoyt RF, Arai AE. Retrospective determination of the area at risk for reperfused acute myocardial infarction with T2-weighted cardiac magnetic resonance imaging: histopathological and displacement encoding with stimulated echoes (DENSE) functional validations. Circulation 2006; 113 (15): 1865-1870.

30. Kim RJ, Wu E, Rafael A, Chen EL, Parker MA, Simonetti O, Klocke FJ et al. The use of contrast-enhanced magnetic resonance imaging to identify reversible myocardial dysfunction. N Engl J Med 2000; 343 (20): 1445-1453.

31. Kumar A, Abdel-Aty H, Kriedemann I, Schulz-Menger J, Gross CM, Dietz R, Friedrich MG. Contrast-enhanced cardiovascular magnetic resonance imaging of right ventricular infarction. J Am Coll Cardiol 2006; 48 (10): 1969-1976.

32. Grothoff M, Elpert C, Hoffmann J, Zachrau J, Lehmkuhl L, de Waha S, Desch S et al. Right ventricular injury in ST-elevation myocardial infarction: risk stratification by visualization of wall motion, edema, and delayed-enhancement cardiac magnetic resonance. Circ Cardiovasc Imaging 2012; 5 (1): 60-68.

33. Miszalski-Jamka T, Klimeczek P, Tomala M, Krupiński M, Zawadowski G, Noelting J, Lada $\mathrm{M}$ et al. Extent of RV dysfunction and myocardial infarction assessed by CMR are independent outcome predictors early after STEMI treated with primary angioplasty. JACC Cardiovasc Imaging 2010; 3 (12): 1237-1246.

34. Tomala M, Miszalski-Jamka T, Zajdel W, Nawrotek B, Mazur W, Kereiakes DJ, Zmudka K. Angiographic result of index PCI determines the presence of right ventricular infarction in patients with acute inferior myocardial infarction. Int J Cardiovasc Imaging 2015; 31 (8): 1591-601.

35. Bowers TR, O'Neill WW, Grines C, Pica MC, Safian RD, Goldstein JA. Effect of reperfusion on biventricular function and survival after right ventricular infarction. N Engl J Med 1998; 338 (14): 933-940.

36. Bowers TR, O'neill WW, Pica M, Goldstein JA. Patterns of coronary compromise resulting in acute right ventricular ischemic dysfunction. Circulation 2002; 106 (9): 1104-1109.

37. Goldstein JA. Pathophysiology and management of right heart ischemia. J Am Coll Cardiol 2002; 40 (5): 841-853.

38. Goldstein JA, Vlahakes GJ, Verrier ED, Schiller NB, Botvinick E, Tyberg JV, Parmley WW et al. Volume loading improves low cardiac output in experimental right ventricular infarction. J Am Coll Cardiol 1983; 2 (2): 270-278.

39. Ondrus T, Kanovsky J, Novotny T, Andrsova I, Spinar J, Kala P. Right ventricular myocardial infarction: From pathophysiology to prognosis. Exp Clin Cardiol 2013; 18 (1): 27-30.

40. Dell'Italia LJ, Starling MR, Blumhardt R, Lasher JC, O'Rourke RA. Comparative effects of volume loading, dobutamine, and nitroprus- side in patients with predominant right ventricular infarction. Circulation 1985; 72 (6): 1327-1335.

41. Parissis H, Graham V, Lampridis S, Lau M, Hooks G, Mhandu PC. IABP: history-evolution-pathophysiology-indications: what we need to know. J Cardiothorac Surg 2016; 11 (1): 122.

42. Goldstein JA, Kern MJ. Percutaneous mechanical support for the failing right heart. Cardiol Clin 2012; 30 (2): 303-310.

43. Anderson M, Morris DL, Tang D, Batsides G, Kirtane A, Hanson I, Meraj P et al. Outcomes of patients with right ventricular failure requiring short-term hemodynamic support with the Impella RP device. J Heart Lung Transplant 2018; 37 (12): 1448-1458.

44. Gramegna M, Beneduce A, Bertoldi LF, Pagnesi M, Marini C, Pazzanese V, Camici PG et al. Impella RP support in refractory right ventricular failure complicating acute myocardial infarction with unsuccessful right coronary artery revascularization. Int J Cardiol 2020; 302: 135-137.

45. Kapur NK, Paruchuri V, Jagannathan A, Steinberg D, Chakrabarti AK, Pinto D, Aghili $\mathbf{N}$ et al. Mechanical Circulatory Support for Right Ventricular Failure. JACC Heart Fail 2013; 1 (2): 127-134.

46. Bernhardt AM, De By TMMH, Reichenspurner H, Deuse T. Isolated permanent right ventricular assist device implantation with the HeartWare continuous-flow ventricular assist device: first results from the European Registry for Patients with Mechanical Circulatory Support. Eur J Cardio-Thorac Surg Off J Eur Assoc Cardio-Thorac Surg 2015; 48 (1): $158-162$.

47. Ghio S, Gavazzi A, Campana C, Inserra C, Klersy C, Sebastiani $\mathbf{R}$, Arbustini $\mathbf{E}$ et al. Independent and additive prognostic value of right ventricular systolic function and pulmonary artery pressure in patients with chronic heart failure. J Am Coll Cardiol 2001; 37 (1): 183-188.

48. Gorter TM, Hoendermis ES, Veldhuisen DJ van, Voors AA, Lam CSP, Geelhoed B, Willems TP et al. Right ventricular dysfunction in heart failure with preserved ejection fraction: a systematic review and meta-analysis. Eur J Heart Fail 2016; 18 (12): 1472-1487.

49. Nass N, McConnell MV, Goldhaber SZ, Chyu S, Solomon SD. Recovery of regional right ventricular function after thrombolysis for pulmonary embolism. Am J Cardiol 1999; 83 (5): 804-806, A10.

50. Zehender M, Kasper W, Kauder E, Schonthaler M, Geibel A, Olschewski M, Just H. Right Ventricular Infarction as an Independent Predictor of Prognosis after Acute Inferior Myocardial Infarction. N Engl J Med 1993; 328 (14): 981-988.

51. Mehta SR, Eikelboom JW, Natarajan MK, Diaz R, Yi C, Gibbons RJ, Yusuf S. Impact of right ventricular involvement on mortality and morbidity in patients with inferior myocardial infarction. J Am Coll Cardiol 2001; 37 (1): 37-43.

52. Jacobs AK, Leopold JA, Bates E, Mendes LA, Sleeper LA, White H, Davidoff $\mathbf{R}$ et al. Cardiogenic shock caused by right ventricular infarction: a report from the SHOCK registry. J Am Coll Cardiol 2003; 41 (8): 1273-1279.

53. O'Neill W, Timmis GC, Bourdillon PD, Lai $P$, Ganghadarhan V, Walton J, Ramos R et al. A Prospective Randomized Clinical Trial of Intracoronary Streptokinase versus Coronary Angioplasty for Acute Myocardial Infarction. N Engl J Med Boston 1986; 314 (13): 812-818.

54. Grines CL, Browne KF, Marco J, Rothbaum D, Stone GW, O'Keefe J, Overlie P et al. A Comparison of Immediate Angioplasty with Thrombolytic Therapy for Acute Myocardial Infarction. Engl J Med 1993; 328 (10): 673-679. 
55. Andersen HR, Nielsen TT, Rasmussen K, Thuesen L, Kelbaek H, Thayssen $\mathbf{P}$, Abildgaard $\mathbf{U}$ et al. A comparison of coronary angioplasty with fibrinolytic therapy in acute myocardial infarction. N Engl J Med 2003; 349 (8): 733-742.

56. Verani MS, Tortoledo FE, Batty JW, Raizner AE. Effect of coronary artery recanalizatiori on right ventricular function in patients with acute myocardial infarction. J Am Coll Cardiol 1985; 5 (5): $1029-1035$.

57. Foussas SG, Zairis MN, Tsiaousis GZ, Theodossis-Georgilas A, Prekates AA, Kontos CF, Makrygiannis SS et al. The impact or right ventricular involvement on the postdischarge long-term mortality in patients with acute inferior ST-segment elevation myocardial infarction. Angiology 2010; 61 (2): 179-183.

58. Berger PB, Ruocco Jr NA, Ryan TJ, Jacobs AK, Zaret BL, Wackers FJ, Frederick MM et al. Frequency and significance of right ventricular dysfunction during inferior wall left ventricular myocardial infarction treated with thrombolytic therapy (results from the Thrombolysis in Myocardial Infarction [TIMI] II trial). Am J Cardiol 1993; 71 (13): $1148-1152$.
59. Kinn JW, Ajluni SC, Samyn JG, Bates ER, Grines CL, O'Neill W. Rapid hemodynamic improvement after reperfusion during right ventricular infarction. J Am Coll Cardiol 1995; 26 (5): 1230-1234.

60. Bowers TR, O'Neill WW, Grines C, Pica MC, Safian RD, Goldstein JA. Effect of reperfusion on biventricular function and survival after right ventricular infarction. N Engl J Med 1998; 338 (14): 933-940.

61. Anavekar NS, Skali H, Bourgoun M, Ghali JK, Kober L, Maggioni AP, McMurray JJV et al. Usefulness of Right Ventricular Fractional Area Change to Predict Death, Heart Failure, and Stroke Following Myocardial Infarction (from the VALIANT ECHO Study). Am J Cardiol 2008; 101 (5): 607-612.

62. Antoni ML, Scherptong RWC, Atary JZ, Boersma E, Holman ER, van der Wall EE, Schalij MJ et al. Prognostic value of right ventricular function in patients after acute myocardial infarction treated with primary percutaneous coronary intervention. Circ Cardiovasc Imaging 2010; 3 (3): 264-71.

Received March 11, 2021. Accepted March 16, 2021. 